\title{
Correction to: Effect of $b$ values and size of region of interest on apparent diffusion coefficient measurement and its reproducibility in liver diffusion-weighted MRI
}

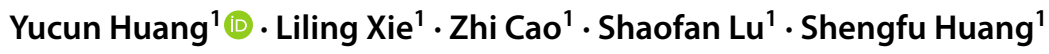

Published online: 9 July 2021

(c) Springer Nature Singapore Pte Ltd. 2021

Correction to: Chinese Journal of Academic Radiology (2021) 4:56-62 https://doi.org/10.1007/s42058-021-00053-7

The original version of this article, published on February 21, 2021, contained a mistake.

The first and last names were presented incorrectly. The original article has been corrected.

Publisher's Note Springer Nature remains neutral with regard to jurisdictional claims in published maps and institutional affiliations.

The original article can be found online at https://doi.org/10.1007/ s42058-021-00053-7.

Yucun Huang

hycun@126.com

1 Department of Radiology, The Fifth People's Hospital

of Zhuhai, Zhuhai, Guangdong, China 